\title{
Experimental and Parameterization Method for Evaluation of Dry Deposition of S Compounds to Natural Surfaces
}

\author{
Ranjit Kumar $^{1}$, K. Maharaj Kumari ${ }^{2 *}$ \\ ${ }^{1}$ Department of Applied Sciences, Technical College, Agra, India \\ ${ }^{2}$ Department of Chemistry, Faculty of Science, Dayalbagh Educational Institute, Agra, India \\ Email: rkschem@rediffmail.com, maharajkumari.k@rediffmail.com
}

Received March 10, 2012; revised April 15, 2012; accepted April 27, 2012

\begin{abstract}
This paper deals with parameterization method based on meteorological parameters for calculation of dry deposition of $\mathrm{S}$ compounds on natural surface (leaf of Cassia siamea) and direct measurement method. A scheme based on meteorological parameters has been evolved to calculate the dry deposition theoretically and a computer program has been developed. Experimentally dry deposition flux of S on leaf of Cassia siamea was measured by exposing the leaf surfaces on non-dewy, non-foggy and non rainy days and washing the leaf surfaces with deionised water and samples were analyzed by Dionex Dx-500 Ion Chromatograph. Atmospheric concentration of $\mathrm{SO}_{2}$ was $3.54 \pm 1.41 \mu \mathrm{g} \cdot \mathrm{m}^{-3}$ and particulate $\mathrm{SO}_{4}^{2-}$ was $2.72 \pm 1.15 \mu \mathrm{g} \cdot \mathrm{m}^{-3}$. Theoretically obtained dry deposition velocity of $\mathrm{SO}_{2}$ and $\mathrm{SO}_{4}^{2-}$ are $0.32 \mathrm{~cm} \cdot \mathrm{s}^{-1}$ and $0.75 \mathrm{~cm} \cdot \mathrm{s}^{-1}$, respectively. The calculated deposition of $\mathrm{S}$ as total sulphate (gaseous $\mathrm{SO}_{2}$ and particulate $\mathrm{SO}_{4}^{2-}$ ) to Cassia leaf was $2.05 \pm 0.78 \mathrm{mg} \cdot \mathrm{m}^{-2} \cdot \mathrm{d}^{-1}$ and experimentally obtained dry deposition of $\mathrm{S}$ as sulphate was $1.07 \pm 1.35$ $\mathrm{mg} \cdot \mathrm{m}^{-2} \cdot \mathrm{d}^{-1}$. The experimentally and theoretically obtained mean values for $\mathrm{S}$ as $\mathrm{SO}_{4}^{2-}$ are comparable.
\end{abstract}

Keywords: Flux; Deposition Velocity; Parameterization; Sulphur; Gas and Particulate

\section{Introduction}

Atmospheric pollutants are deposited to ecosystems primarily through wet deposition and dry deposition. Dry deposition includes gases and particles. The primary gases of major concern are nitric acid $\left(\mathrm{HNO}_{3}\right)$, and sulfur dioxide $\left(\mathrm{SO}_{2}\right)$, while the primary particles are nitrate $\left(\mathrm{NO}_{3}^{-}\right)$and sulfate $\left(\mathrm{SO}_{4}^{2-}\right)$ ions (Hanson and Lindberg, 1991 [1]). Sulphur is ubiquitous in nature and exists in soil as organic compounds and as sulphur or sulphide, in sea water as sulphate, in plants as sulphite, sulphide or organic compound and in the atmosphere in gaseous and solid states (Delmas and Servant, 1988 [2]). Sulphur compounds have been considered as one of the potential acidifying agents. Although much progress has been made to control sulfur dioxide emissions, deposition of sulfur (S) compounds continues to be a problem in Asia, as a result, certain sensitive freshwater lakes and streams continue to lose acid-neutralizing capacity (ANC) and sensitive soils continue to be acidified. These acids result from atmospheric oxidation of the sulfur dioxide $\left(\mathrm{SO}_{2}\right)$ released into the atmosphere during the smelting of ores

"Corresponding author. and from burning of fuels with the high sulfur content and many other sources (Galloway et al., 1984 [3]).

Dry deposition is one of the major mechanisms by which air pollutants can be delivered to sensitive surfaces. This process is governed by the concentration in air and by turbulent transport processes in the boundary layer, by the chemical and physical nature of the depositing species and by the capability of the surface to capture or absorb gases and particles (Hicks et al., 1987 [4]). Dry deposition is usually characterized by deposition velocity $(\mathrm{Vd})$, which is defined as the flux (F) of the species (S) to the surface divided by the concentration [S] at some reference height:

$$
V_{\mathrm{d}}=\frac{-F}{[S]}
$$

The amount of the species deposited per unit area per second in a geographical location, i.e., the flux, can be calculated if the deposition velocity and the pollutant concentration are known. The deposition velocity is also frequently related to resistance $(\mathrm{r})$ :

$$
V_{\mathrm{d}}=\frac{1}{R}
$$


By analogy to electrical systems, the resistance $R$ can be thought of as being comprised of several components in dry deposition to ground are separated (Thom, 1975 [5]; Garland, 1977 [6]; Wesley and Hicks, 1977 [7]; Fowler, 1978 [8]): the aerodynamic resistance $\left(R_{\mathrm{a}}\right)$, the quasilaminar resistance $\left(R_{\mathrm{b}}\right)$ and Canopy or surface resistance $\left(R_{\mathrm{c}}\right)$. The inverse of the sum of the resistances gives the deposition velocity,

$$
V_{\mathrm{d}}=\frac{1}{R_{\mathrm{a}}+R_{\mathrm{b}}+R_{\mathrm{c}}}
$$

Dry deposition is much more difficult to estimate than wet deposition. The estimation of dry deposition rates requires information on the ambient concentrations of pollutants, meteorological data, and information on land use, vegetation, and surface conditions, all of which are site-specific. Because of this site-specificity, it is difficult to spatially extrapolate dry deposition data, as is often done for wet deposition data.

A broad range of techniques has been used to measure dry deposition (Businger, 1986 [9]). It can be divided into two general categories: direct and indirect. Direct method includes surrogate surfaces, natural surfaces, chamber method, eddy correlation and eddy accumulation methods for estimation of dry deposition. An indirect method includes gradient method, inferential method for determining dry deposition (Seinfeld and Pandis, 1998 [10]). Many dry deposition models (Acid Deposition and Oxidant Model, Regional Acid Deposition Model, Dutch Empirical Acid Deposition Model) have been developed during the past ten years and efforts continue to improve their capabilities (Wesley and Hicks, 2000 [11]). The dry deposition module in the Acid Deposition and Oxidant Model (ADOM) was initially developed in the early 1980s (Pleim et al., 1984 [12]) and has undergone testing and revisions (Padro and Edwards, 1991 [13]; Padro, 1996 [14]). The Regional Acid Deposition Model (RADM) has a dry deposition module (Chang et al., 1987 [15]; Walcek et al., 1986 [16]), the latest completed version of which was also described (Wesley, 1989 [17]; Walmsley and Wesley, 1996 [18]). Several models have been developed in Europe viz., the Estimation of Deposition of Acidifying Components in Europe (EDACS) and the Dutch Empirical Acid Deposition Model (DEADM) have been used with long-range modules to map modeled deposition amounts for sulphur and nitrogen compounds (Erisman and Draaijers, 1995 [19]). Parameterization methods have been developed and tested extensively (Voldner et al., 1986 [20]; Hicks et al., 1985 [21]; Meyers and Baldochhi, 1988 [22]; Wesley, 1989 [17]; Matt and Womack, 1989 [23]; Padro et al., 1991 [24]; Stocker et al., 1993 [25]). In all the studies assumptions and presumptions have been made. All these study have limitations and need further im- provements (Wesley and Hicks, 2000 [11]).

Direct measurement of dry deposition is expensive and cumbersome in long-term measurements, so, an alternate method was required to calculate the dry deposition. Dry deposition can be determined by parameterization method by calculating the three resistances $\left(R_{\mathrm{a}}, R_{\mathrm{b}}\right.$, and $\left.R_{\mathrm{c}}\right)$ governing dry deposition. In earlier reported studies determination of $R_{\mathrm{a}}, R_{\mathrm{b}}$, and $R_{\mathrm{c}}$ together has not been made. Hence, the present study was planned to determine aerodynamic resistance $\left(R_{\mathrm{a}}\right)$, quassilaminar resistance $\left(R_{\mathrm{b}}\right)$ and surface resistance $\left(R_{\mathrm{c}}\right)$ using meteorological data and to calculate the deposition flux and compare it with experimentally determined dry deposition flux to leaf of Cassia (Cassia siamea) plant. As theoretical calculations require numerous steps a computer program has been developed. The present study is more accurate, realistic and rigorous.

\section{Methods and Materials}

\subsection{Theoretical Calculation}

In the present study dry deposition velocity was calculated by simulating the different processes that govern the dry deposition. The deposition velocity for gases is based on

$$
V_{\mathrm{d}}=\frac{1}{R_{\mathrm{a}}+R_{\mathrm{b}}+R_{\mathrm{c}}}
$$

and that for particles on

$$
V_{\mathrm{d}}=\frac{1}{R_{\mathrm{a}}+R_{\mathrm{b}}+R_{\mathrm{a}} R_{\mathrm{b}} V_{\mathrm{s}}}+V_{\mathrm{s}}
$$

where,

$$
\begin{aligned}
& R_{\mathrm{a}}=\text { aerodynamic resistance, } \\
& R_{\mathrm{b}}=\text { quassilaminar resistance, } \\
& R_{\mathrm{c}}=\text { surface resistance, } \\
& V_{\mathrm{s}}=\text { settling velocity }
\end{aligned}
$$

To calculate the $V_{\mathrm{d}}$, the aerodynamic resistance $\left(R_{\mathrm{a}}\right)$, quassilaminar resistance $\left(R_{\mathrm{b}}\right)$ and surface resistance $\left(R_{\mathrm{c}}\right)$ were calculated by computing the values of meteorological data.

\section{Aerodynamic Resistance}

The aerodynamic resistance for both gases and particle is calculated by

$$
R_{\mathrm{a}}=4\left(u \sigma \theta^{2}\right)^{-1}
$$

in neutral and stable stratification while in unstable condition the equation is

$$
R_{\mathrm{a}}=9\left(u \sigma \theta^{2}\right)^{-1}
$$

where, $u=$ mean wind speed and $\sigma \theta=$ standard deviation of wind direction.

\section{Quasilaminar Resistance}

The quasilaminar resistances for gases and particles 
are calculated as

$$
R_{\mathrm{b}}=5^{*}(S c)^{2 / 3} / u_{*}
$$

for gases

$$
R_{\mathrm{b}}=1 / u^{*}\left(S c^{-2 / 3}+10^{-3 / S t}\right)
$$

for particles

where $u_{*}$ is the friction velocity (root mean covariance between horizontal and vertical velocity components), the $S c$ is the Schmidt number of species. The Schmidt number of species is calculated as $S c=v / \mathrm{D}$. The viscosity (v) of air at $20^{\circ} \mathrm{C}$ is $0.15 \mathrm{~cm}^{2} \cdot \mathrm{s}^{-1}$ at sea level and D is molecular (for gas) and Brownian (for particles) diffusivities (Hicks et al., 1985 [21]). Table 1 presents the values of diffusivities $\left(\mathrm{cm} \cdot \mathrm{s}^{-1}\right)$ and Schmidt number of the species. St is stokes number and calculated as $V_{s} u_{*}{ }^{2} / \mathrm{g}$ $v$. Here $V_{s}$ is settling velocity and for particles it was calculated by

$$
V \mathrm{~S}=\frac{\rho_{\mathrm{p}} D_{p}^{2} g C_{c}}{18 \mu}
$$

where,

$\rho_{\mathrm{p}}=$ density of the particle

$D_{\mathrm{p}}=$ particle diameter

$g=$ gravitational acceleration

$C_{c}=$ slip correction factor and

$\mu=$ Viscosity of air

Here unit density of the particle has been assumed and the gravitational acceleration $9.8 \mathrm{~m} \cdot \mathrm{s}^{-2}$ at sea level has been considered. The slip correction factor is given in Table 2.

\section{Surface Resistance}

The surface or canopy resistance $R_{\mathrm{c}}$ poses the most complexity in specifying a quantitative model $\left(R_{\mathrm{c}}\right.$ is assumed to be zero for particles and thus in developing a model for $R_{\mathrm{c}}$ only gases are considered) (Seinfled and

Table 1. Molecular (for gases) and Brownian (for particles)

\begin{tabular}{|c|c|c|}
\hline & D & $\mathbf{S}_{\mathbf{c}}$ \\
\hline \multicolumn{3}{|c|}{ Gaseous species } \\
\hline Sulphur dioxide & 0.12 & 1.25 \\
\hline \multicolumn{3}{|c|}{ Particles (unit density) } \\
\hline $10^{-3}$ & $1.28 \times 10^{-2}$ & $1.17 \times 10^{1}$ \\
\hline $10^{-2}$ & $1.35 \times 10^{-4}$ & $1.11 \times 10^{3}$ \\
\hline $10^{-1}$ & $2.21 \times 10^{-6}$ & $6.79 \times 10^{4}$ \\
\hline 1 & $1.27 \times 10^{-7}$ & $1.18 \times 10^{6}$ \\
\hline 10 & $1.38 \times 10^{-8}$ & $1.09 \times 10^{7}$ \\
\hline
\end{tabular}
diffusivities $\left(\mathrm{D} ; \mathrm{cm}^{2} / \mathrm{s}\right)$ for a range of pollutants and deduced values of Schmidt number $\left(S_{c}\right)$.

Source: Hicks et al., 1985(NOAA Technical Memorandum)(19).
Table 2. Slip correction factor $\mathrm{Cc}$ for spherical particles in air at $298 \mathrm{~K}$ and $1 \mathrm{~atm}$.

\begin{tabular}{cc}
\hline $\mathrm{Dp}(\mu \mathrm{m})$ & $\mathrm{Cc}$ \\
\hline 0.001 & 216 \\
0.002 & 108 \\
0.005 & 43.6 \\
0.01 & 22.2 \\
0.02 & 11.4 \\
0.05 & 4.95 \\
0.1 & 2.85 \\
0.2 & 1.865 \\
0.5 & 1.326 \\
1.0 & 1.164 \\
2.0 & 1.082 \\
5.0 & 1.032 \\
10.0 & 1.016 \\
20.0 & 1.008 \\
50.0 & 1.003 \\
100.0 & 1.0016 \\
\hline
\end{tabular}

Source: Seinfeld and Pandis, 1998(8).

Pandis, 1998 [10]). For all land use categories, the surface resistance is divided into component resistances. $R_{\mathrm{c}}$ as applied to vegetations is denoted as $R_{\mathrm{cf}}$. The surface resistance for foliar is calculated from individual resistance by

$$
R_{\mathrm{cf}}=\left(1 / R_{\mathrm{cut}}+1 / R_{\mathrm{st}}+R_{\mathrm{m}}\right)^{-1}(L A I)^{-1}
$$

where, $R_{\mathrm{cf}}$ is the foliar resistance, $R_{\text {cut }}$ is cuticular resistance, $R_{\mathrm{st}}$ is stomatal resistance, $R_{\mathrm{m}}$ is mesophyll resistance and $L A I$ is leaf area index. The leaf area index ( $L A I)$ is the total active area of foliage per unit area of the earth's surface. The calculated leaf area index of canopy of Cassia is 2.62 .

The specific locations of gaseous removal often depend on the plant's biological activity level. The mesophyll resistance $R_{\mathrm{m}}$ depends on the solubility of the gas (26). Readily soluble gases such as $\mathrm{SO}_{2}$ are assumed to experience no resistance as the mesophyll (Seinfled and Pandis, 1998 [10]).

The bulk canopy stomatal resistance is calculated from the solar radiation $\left(\mathrm{G}\right.$ in $\left.\mathrm{W} \cdot \mathrm{m}^{-2}\right)$, and surface air temperature $\left(\mathrm{Ts}\right.$ in ${ }^{\circ} \mathrm{C}$ ) (between $0^{\circ} \mathrm{C}$ and $40^{\circ} \mathrm{C}$ ) using

$$
R_{\mathrm{st}}=r j\left[1+(200 / G+0.1)^{2}(400 / T s(40-T s))\right]
$$

where $\mathrm{rj}$ is the minimum bulk canopy stomatal resistance for water vapours. The input resistance $\left(\mathrm{s} \cdot \mathrm{m}^{-1}\right) \mathrm{rj}$ for computation of surface resistance for summer, monsoon and winter seasons are 130, 250, and 400 for coniferous forest (Wesley, 1989 [17]).

The combined minimum stomatal and mesophyll resistance is calculated from

$$
R_{\mathrm{sm}}=R_{\mathrm{st}}+R_{\mathrm{m}}=R_{\mathrm{st}} \frac{D H_{2} \mathrm{O}}{D i}+\frac{1}{3.3 \times 10^{-4} H_{i}^{*}+100 f_{0}^{1}}(10)
$$

where $\mathrm{DH}_{2} \mathrm{O} / \mathrm{Di}$ is the ratio of the molecular diffusivities of water to that of the specific gas $\left(\mathrm{SO}_{2}=1.89\right), H_{i}^{*}$ is the 
effective Hennry's law constant $\left(\mathrm{M} \cdot \mathrm{atm}^{-1}\right)$ for the gas $\left(\mathrm{SO}_{2}=1 \times 10^{5}\right)$ and $f_{o}^{i}$ is a normalized (0 to 1$)$ reactivity factor for the dissolved gases $\left(\mathrm{SO}_{2}=0\right)$ (Seinfled and Pandis, 1998 [10]).

Transfer of gases through the cuticle is generally less important than that through the stomata and can be neglected. Typical values for $R_{\text {cut }}$ for water vapor diffusion through leaf surfaces are $30-200 \mathrm{~s} \cdot \mathrm{cm}^{-1}$, as compared with values of $R_{\mathrm{st}}$ in the range 1 to $20 \mathrm{~s} \cdot \mathrm{cm}^{-1}$. For $\mathrm{SO}_{2}$, cuticle resistance far exceeds the stomatal resistance (Van Hove, 1989 [26]). This resistance is observed to decrease as relative humidity increases. In general, for
$\mathrm{SO}_{2} R_{\text {cut }}$ has been considered to be $100 \mathrm{~s} \cdot \mathrm{cm}^{-1}$.

By substituting required data in equations (i-x), $\mathrm{R}_{\mathrm{a}}, \mathrm{R}_{\mathrm{b}}$, $R_{\mathrm{c}}, V_{\mathrm{s}}$ and $V_{\mathrm{d}}$ for $\mathrm{SO}_{2}$, and particulate $\mathrm{SO}_{4}^{2-}$ were calculated. The calculated deposition velocities were multiplied with their respective atmospheric concentrations to get the deposition flux.

As so many parameters and calculation steps are involved in computation of dry deposition velocity, a computer program was developed to make the method fast, convenient and more useful. Figure 1 shows the algorithm of computer program for calculation of dry deposition velocity and flux by present method.

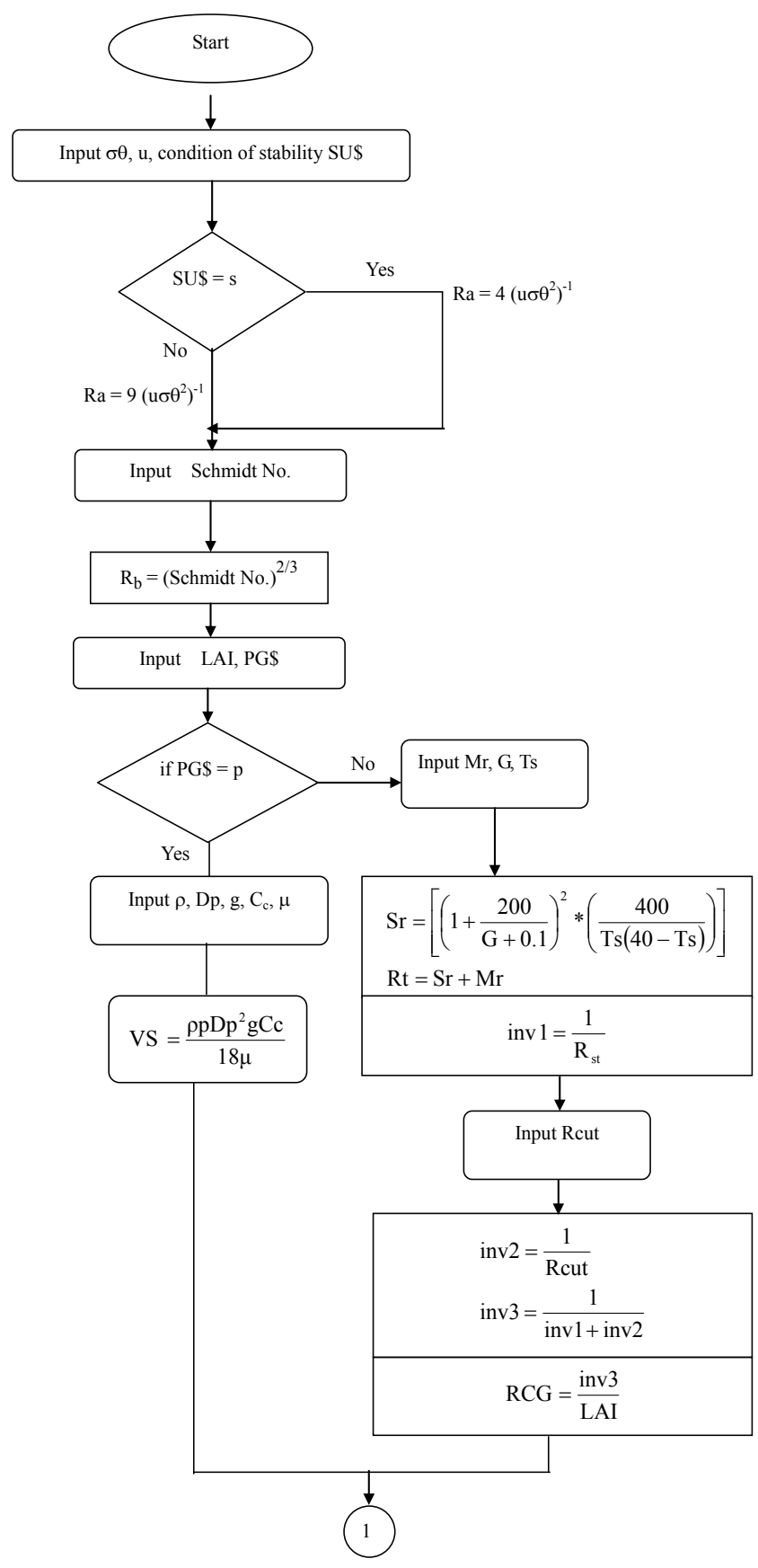




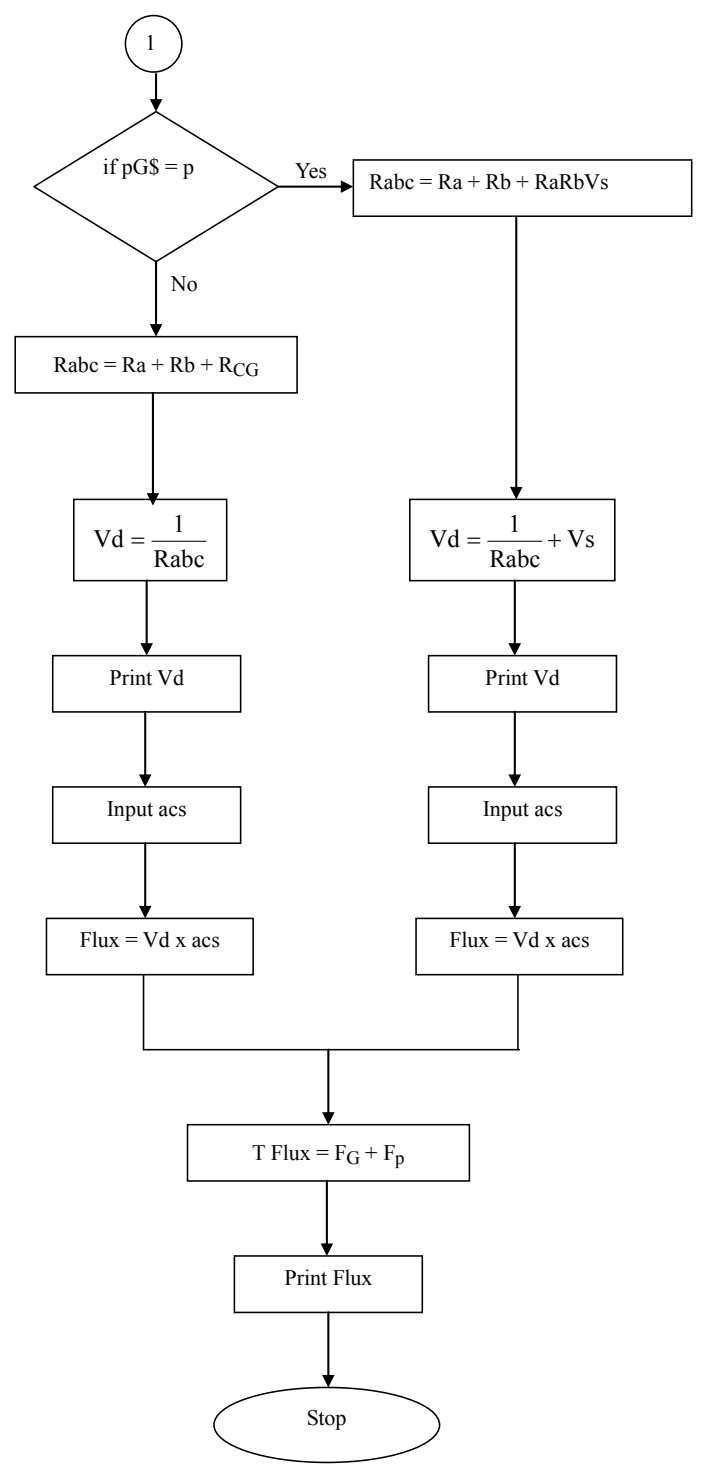

Figure 1. Algorithm of parameterization method to compute dry deposition.

\subsection{Experimental}

\subsubsection{Site Description}

The sampling site is Dayalbagh located at Agra (North Central India, $27^{\circ} 10^{\prime} \mathrm{N}, 78^{\circ} 05^{\prime} \mathrm{E}$ ), which is about $200 \mathrm{~km}$ southeast of Delhi. It is situated in a semi arid zone. Dayalbagh is a suburban site that is located in the north of the city. The site is $10 \mathrm{~km}$ away from the industrial sector of the city. Due to agricultural practices, vegetation predominates. Apart from the local sources, Mathura refinery and Ferozabad glass industries are both situated at a distance of $40 \mathrm{~km}$ west and east, respectively from Agra.

\subsubsection{Sample Collection} Dry Deposition

Dry deposition samples were collected from four paired leaves of Cassia (Cassia siamea). Cassia is a widely dis- tributed coniferous plant in this semiarid region and canopy was $5.8 \mathrm{~m}$ tall. Cassia is a coniferous plant and stomata are on both sides of the leaves. Four pairs of leaves of Cassia plant were tagged and washed with deionised water using a sprayer prior to collection and air-dried. The dry deposition samples were collected on non-dewy, non-foggy and non rainy days using surface washing method (Davidson et al., 1990 [27]) after $72 \mathrm{~h}$ exposure to get a sufficient quantity of deposited materials for analysis. The deposit on the surface was washed off into polyethylene bottles using a sprayer at the site and volume was made up to $100 \mathrm{ml}$. The sample was centrifuged and the supernatant was treated with chloroform to prevent microbial degradation and frozen at $4^{\circ} \mathrm{C}$. All the plastic wares used for storage were cleaned with deionised water until the conductivity of the washing approaches $1 \mu \mathrm{s}$. 


\section{Measurements in Air Particulate}

Aerosol samples were collected with KIMOTO (CPS105) 4 stage size segregated impactor using high volume sampler (HVS) equipped with automatic flow rate controller at a flow rate of $1000 \mathrm{~L} \cdot \mathrm{min}^{-1}$. The impactor separates particles in air according to their aerodynamic diameter. Predesiccated and preweighed Whatman 41 filters were used as collecting surface. After $24 \mathrm{~h}$ collection period, filters were withdrawn and kept in desiccators. Each filter was extracted in $100 \mathrm{ml}$ deionized water for two hours, kept on ultrasonic bath for half an hour and then filtered through Whatman 41 paper into polyethylene bottles. Samples were treated in the similar manner as dry deposition samples and stored under refrigeration till analysis.

\section{Vapour Phase}

Gaseous $\mathrm{SO}_{2}$ was collected by impinger technique using a low volume sampler comprising a diaphragm reciprocating type of air pump (Model Dymax 2, Charles Austin Pvt. Ltd., England). $\mathrm{SO}_{2}$ samples were collected by aspirating air through measured volume $(50 \mathrm{ml})$ of $0.04 \mathrm{M}$ potassium tetrachloromercurate $\left(\mathrm{K}_{2} \mathrm{HgCl}_{4}\right)(\mathrm{TCM})$ solution at a flow rate of $2 \mathrm{~L} \cdot \mathrm{min}^{-1}$ for $24 \mathrm{~h}$. $\mathrm{SO}_{2}$ was estimated by West and Gaeke method (Harrison and Perry, 1986 [28]).

\subsection{Analysis}

$\mathrm{SO}_{4}^{2-}$ in dry deposition and aerosol samples were measured by Ion chromatography using a Dionex DX-500 Ion chromatograph system equipped with guard column (AS 11A), separator column (AS 11ASC), self regenerating suppressor (SRS) and conductivity detector (CD-20) using $5.5 \mathrm{mM} \mathrm{NaOH}$ as eluent at flow rate of $1 \mathrm{ml} \cdot \mathrm{m}^{-1}$. Vapor phase $\mathrm{SO}_{2}$ was analyzed by UV-Visible Spectrophotometer (Shimadzu Model-1601).

\subsection{Meteorological Parameters}

The meteorological parameters viz., temperature, relative humidity, wind speed, wind direction and solar radiation were monitored at Dayalbagh using a self contained battery operated WDL 1002 Data logger (Dynalab, Pune) system. Table 3 presents the sensors used along with resolution and accuracy of meteorological parameters. The data was collected for the study period July 1999 to June 2001. Arithmetic mean, standard deviation, minimum and maximum of meteorological parameters, which are used for model calculation, are presented in Table 4.

\subsection{Uncertainty (Experimental and Analytical)}

As a careful analysis of errors is essential in an experiment of present type, numerous calibrations including collection of field blank, repeatability, instruments analytical precision, accuracy and detection limits etc. have been done.

1) The instrument Dionex DX-500 Ion Chromatograph was calibrated daily with fresh working standard solution of 2 ppm, prepared daily from 1000 ppm stock standard solutions of $\mathrm{SO}_{4}^{2-}$. Although the standard peak heights never changed by more than a few percent throughout the day and the variation in peak area was found to be less than $5 \%$; instrument was recalibrated after every five samples.

2) Analytical uncertainties arise from the non-ideal chemical or physical behavior of analytical systems.

The term precision is used to describe the reproducibility of results. In order to calculate the precision a standard of $1 \mathrm{ppm}$ was run for nine times and the precision reported as deviation from the mean in terms of percentage.

The term accuracy denotes the nearness of a measurement to its accepted value and is expressed in terms of error. The accuracy was calculated by the difference between observed value Xo and the accepted value Xa.

\section{$\mathrm{A}=\mathrm{Xo}-\mathrm{Xa}$}

In this expression the accepted value may itself be subjected to considerable uncertainty so the more realistic term is relative error, which is error in terms of percentage. The accuracy has been calculated in terms of relative errors (\%). Analytical precision, accuracy and detection limits of instruments for $\mathrm{SO}_{4}^{2-}$ are $1.1 \%, 6.3 \%$ and $0.12 \mu \mathrm{g} \cdot 1^{-1}$, respectively.

3) Field blank for dry deposition to leaf surfaces were collected in the same manner as dry deposition samples by exposing leaves for one minute to see the ion leakage during washing (leaching) the leaves. The samples of field blank were treated and analyzed and were found to be below detection limit.

4) Field blanks for particulate samples were also collected by mounting the Whatman filter paper in the sampler and putting the system on just for 1 minute. The concentration of analytes was found to be close to detection limits. Field blank for vapor phase $\mathrm{SO}_{2}$ was collected for one minute following the same procedure as for sample

Table 3. Sensors used, resolution and accuracy of meteorological parameters.

\begin{tabular}{ccccc}
\hline $\begin{array}{c}\text { Measurement } \\
\text { Parameters }\end{array}$ & Sensors & Resolution & Accuracy & Units \\
\hline Wind speed & $\begin{array}{c}3 \text { Cup } \\
\text { Anemometer }\end{array}$ & - & $\pm 2 \%$ & $\mathrm{~m} / \mathrm{s}$ \\
Wind direction & Wind vane & $1^{\circ}$ & $\pm 3^{\circ}$ & Degree \\
$\begin{array}{c}\text { Relative } \\
\text { humidity }\end{array}$ & $\begin{array}{c}\text { Solid state } \\
\text { capacitive type } \\
72 \text { element } \\
\text { thermopile } \\
\text { Solar radiation }\end{array}$ & $0.1 \%$ & $\begin{array}{c}3 \% \text { of full } \\
\text { scale reading }\end{array}$ & - of full scale \\
Ambient & $\begin{array}{c}\text { Platinum } \\
\text { resistance }\end{array}$ & $0.1^{\circ} \mathrm{C}$ & $0.2^{\circ} \mathrm{C}$ & ${ }^{\circ} \mathrm{C}$ \\
temperature & & & & $\mathrm{W} \cdot \mathrm{m}^{-2}$ \\
\hline
\end{tabular}


Table 4. Temperature, relative humidity, solar radiation, wind speed and wind direction of the study period.

\begin{tabular}{|c|c|c|c|c|c|}
\hline & Temperature $\left({ }^{\circ} \mathrm{C}\right)$ & Relative humidity (\%) & Solar Radiation $\left(\mathrm{W} \cdot \mathrm{m}^{-2}\right)$ & Wind Speed $\left(\mathrm{m} \cdot \mathrm{s}^{-1}\right)$ & Wind Direction \\
\hline \multicolumn{6}{|c|}{ Winter } \\
\hline Arithmetic mean & 16.08 & 70.95 & 573.13 & 1.66 & $\mathrm{~W}, \mathrm{NW}, \mathrm{NE}$ \\
\hline Standard deviation & 3.24 & 9.88 & 154.29 & 0.33 & $45^{\circ}$ \\
\hline Minimum & 11.1 & 52.3 & 365.0 & 1.14 & \\
\hline Maximum & 23.0 & 87.8 & 732.5 & 2.83 & \\
\hline \multicolumn{6}{|c|}{ Summer } \\
\hline Arithmetic mean & 33.04 & 51.28 & 982.08 & 1.87 & W, NW, SW \\
\hline Standard deviation & 3.10 & 16.31 & 238.86 & 0.68 & $45^{\circ}$ \\
\hline Minimum & 25.1 & 24.1 & 620.0 & 0.91 & \\
\hline Maximum & 39.2 & 83.0 & 1330.0 & 2.56 & \\
\hline \multicolumn{6}{|c|}{ Monsoon } \\
\hline Arithmetic mean & 30.43 & 71.49 & 847.94 & 1.96 & $\mathrm{~W}, \mathrm{SW}, \mathrm{NW}, \mathrm{NE}$ \\
\hline Standard deviation & 1.66 & 12.20 & 250.54 & 0.53 & $67.5^{\circ}$ \\
\hline Minimum & 28.1 & 45.19 & 370.0 & 1.11 & \\
\hline Maximum & 34.25 & 86.3 & 1128.25 & 2.92 & \\
\hline \multicolumn{6}{|c|}{ Annual } \\
\hline Arithmetic mean & 25.79 & 63.98 & 872.73 & 1.88 & NW, W \\
\hline Standard deviation & 8.36 & 16.09 & 266.7 & 0.54 & $67.5^{\circ}$ \\
\hline Minimum & 11.1 & 24.10 & 365.0 & 0.91 & \\
\hline Maximum & 39.2 & 87.8 & 1330.0 & 2.92 & \\
\hline
\end{tabular}

collections. Field blank values for vapor phase were found to be below detection limit.

5) Flow rate in collection of trace gases were corrected by checking the flow rate by a calibrated rotameter at an interval of one hour and average values obtained were considered in the calculation.

\section{Results and Discussion}

Table 5 presents the values of aerodynamic resistance (Ra), quassilaminar resistance $(\mathrm{Rb})$, foliar resistance (Rcf), settling velocity (Vs), and deposition velocity (Vd). The theoretically calculated dry deposition velocity of gaseous $\mathrm{SO}_{2}$ ranged between 0.25 to 0.35 and 0.74 to $0.78 \mathrm{~cm} \cdot \mathrm{s}^{-1}$ for particulate $\mathrm{SO}_{4}^{2-}$ on Cassia leaf. It has been seen from the table that dry deposition velocity of particulate $\mathrm{SO}_{4}^{2-}$ are higher than that of gaseous $\mathrm{SO}_{2}$. The reported values for dry deposition velocity lie in the range of 0 to $3.4 \mathrm{~cm} \cdot \mathrm{s}^{-1}$ for $\mathrm{SO}_{2}$ (Fowler, 1978 [8]) and 0.01 to $2.9 \mathrm{~cm} \cdot \mathrm{s}^{-1}$ for $\mathrm{SO}_{4}^{2-}$ (Nicholson, 1988 [29]; Davidson et al., 1990 [27]). The deposition velocity of $\mathrm{SO}_{2}$, and $\mathrm{SO}_{4}^{2-}$ fall in the reported range.
Average annual and seasonal atmospheric concentrations of $\mathrm{SO}_{2}$, and $\mathrm{SO}_{4}^{2-}$ are presented in Table 6. The annual mean atmospheric concentration is $3.54 \pm 1.41$ $\mu \mathrm{g} \cdot \mathrm{m}^{-3}$ for $\mathrm{SO}_{2}$ and $2.72 \pm 1.15 \mu \mathrm{g} \mathrm{m}{ }^{-3}$ for $\mathrm{SO}_{4}^{2-}$. The dry deposition flux of $\mathrm{SO}_{4}^{2-}$ on Cassia leaf is determined experimentally and annual mean value is $1.07 \pm$ $1.35 \mathrm{mg} \cdot \mathrm{m}^{-2} \cdot \mathrm{d}^{-1}$ for $\mathrm{SO}_{4}^{2-}$ (Table 7). To find out the deposition of $\mathrm{SO}_{2}$, and $\mathrm{SO}_{4}^{2-}$, the atmospheric concentration of $\mathrm{SO}_{2}$ and $\mathrm{SO}_{4}^{2-}$ were multiplied with their respective deposition velocity to Cassia leaf. The calculated dry deposition flux of gaseous $\mathrm{SO}_{2}$ is $0.97 \pm 0.4$ $\mathrm{mg} \cdot \mathrm{m}^{-2} \cdot \mathrm{d}^{-1}$ and particulate $\mathrm{SO}_{4}^{2-}$ is $1.76 \pm 0.74 \mathrm{mg} \cdot \mathrm{m}^{-2}$ $\mathrm{d}^{-1}$. In ambient air, rates of oxidation of $\mathrm{SO}_{2}$ up to $\sim 30 \%$ $\mathrm{h}^{-1}$ have been observed (Meszaros et al., 1977 [30]; Alkenzweeny et al., 1977 [31]). So, 30\% of estimated deposition of $\mathrm{SO}_{2}$, i.e., $0.29 \mathrm{mg} \cdot \mathrm{m}^{-2} \cdot \mathrm{d}^{-1}$, would be deposited as sulphate. Depo- sition flux of $\mathrm{S}$ as sulphate (gaseous $\mathrm{SO}_{2}+$ particulate $\mathrm{SO}_{4}^{2-}$ ) would be $2.05 \pm 0.78$ $\mathrm{mg} \cdot \mathrm{m}^{-2} \cdot \mathrm{d}^{-1}$. Experimentally observed dry deposition flux of $\mathrm{SO}_{4}^{2-}$ is $1.07 \pm 1.35 \mathrm{mg} \cdot \mathrm{m}^{-2} \cdot \mathrm{d}^{-1}$, which is comparable to theoretically calculated dry deposition flux of $\mathrm{S}$ as 
Table 5. Aerodynamic resistance $\left(R_{\mathrm{a}}\right)$, quasilaminar resistance $\left(R_{\mathrm{b}}\right)$, stomatal resistance $\left(R_{\mathrm{st}}\right)$, mesophyll resistance $\left(R_{\mathrm{m}}\right)$, cuticular resistance $\left(R_{\mathrm{c}}\right)$, foliar resistance $\left(R_{\mathrm{cf}}\right)$, settling velocity $\left(V_{\mathrm{s}}\right)$ and deposition velocity $\left(V_{\mathrm{d}}\right)$ for gaseous $\mathrm{SO}_{2}$ and particulate $\mathrm{SO}_{4}^{2-}$ as obtained by parameterization method for Cassia leaf.

\begin{tabular}{|c|c|c|c|c|c|c|c|c|}
\hline Species & Seasons & $\begin{array}{l}\text { Aerodynamic } \\
\text { Resistance }\left(R_{\mathrm{a}}\right)\end{array}$ & $\begin{array}{l}\text { Quasilaminar } \\
\text { Resistance }\left(\boldsymbol{R}_{\mathrm{b}}\right)\end{array}$ & $\begin{array}{l}\text { Combined Stomatal } \\
\left(R_{\mathrm{st}}\right) \text { and Mesophyl } \\
\text { Resistance }\left(\boldsymbol{R}_{\mathrm{m}}\right) \\
\end{array}$ & $\begin{array}{l}\text { Cuticular } \\
\text { Resistance } \\
\left(\boldsymbol{R}_{\text {cut }}\right)^{*}\end{array}$ & $\begin{array}{c}\text { Coniferous } \\
\text { Resistance }\left(R_{\mathrm{cf}}\right)\end{array}$ & $\begin{array}{c}\text { Settling } \\
\text { Velocity }\left(V_{\mathrm{s}}\right)\end{array}$ & $\begin{array}{c}\text { Deposition } \\
\text { Velocity }\left(V_{d}\right)\end{array}$ \\
\hline \multirow[t]{4}{*}{$\mathrm{SO}_{2}$} & $\mathrm{~S}$ & 0.078 & 0.96 & 2.66 & 100 & 2.6 & NR & 0.28 \\
\hline & M & 0.033 & 0.96 & 5.11 & 100 & 1.86 & NR & 0.35 \\
\hline & W & 0.039 & 0.96 & 8.54 & 100 & 2.99 & NR & 0.25 \\
\hline & A & 0.058 & 0.96 & 581 & 100 & 2.1 & NR & 0.32 \\
\hline \multirow[t]{4}{*}{$\mathrm{SO}_{4}^{2-}$} & S & 0.078 & 1.36 & NR & NR & NR & 0.38 & 1.14 \\
\hline & M & 0.033 & 1.36 & NR & NR & NR & 0.38 & 1.18 \\
\hline & W & 0.039 & 1.36 & NR & NR & NR & 0.38 & 1.03 \\
\hline & A & 0.058 & 1.36 & NR & NR & NR & 0.38 & 1.16 \\
\hline
\end{tabular}

Note: NR $=$ not required. Source: ${ }^{*}$ Seinfeld and Pandis, 1998

$\mathrm{SO}_{4}^{2-}$ by parameterization method to natural surface (Table 7).

\section{Summary}

Dry deposition velocity on natural surface (leaf Cassia siamea) at Dayalbagh, a suburban site of semiarid region has been calculated by simulating different processes governing dry deposition using meteorological data. A computer program has been developed to make the method more easy and fast. The calculated dry deposition velocity by parameterization method for $\mathrm{SO}_{2}$ and $\mathrm{SO}_{4}^{2-}$ are in the reported range. Atmospheric concentration of

Table 6. Atmospheric concentration $\left(\mu \mathrm{g} \cdot \mathrm{m}^{-3}\right)$ of $\mathrm{SO}_{2}$, and particulate $\mathrm{SO}_{4}^{2-}$.

\begin{tabular}{ccc}
\hline & $\mathrm{SO}_{2}$ & $\mathrm{SO}_{4}^{2-}$ \\
Annual & $3.54 \pm 1.41$ & 2.72 \\
& $(1.60-6.20)$ & $(1.23-4.1)$ \\
Monsoon & $2.72 \pm 0.78$ & $3.97 \pm 0.71$ \\
& $(1.60-3.50)$ & $(2.25-4.1)$ \\
Winter & $4.5 \pm 1.45$ & $1.69 \pm 0.62$ \\
& $(2.50-6.20)$ & $(1.24-2.84)$ \\
Summer & $3.4 \pm 1.5$ & $2.51 \pm 0.56$ \\
& $(1.80-5.10)$ & $(1.23-2.96)$ \\
\hline
\end{tabular}

Note: The values given in parentheses are range.

Table 7. Experimental and calculated dry deposition flux of total $\mathrm{SO}_{4}^{2-}$.

\begin{tabular}{cc}
\hline Species & Total $\mathrm{SO}_{4}^{2-}$ \\
\hline Experimental value & $1.07 \pm 1.35$ \\
& $(0.06-7.86)$ \\
Theoretical value & $2.05 \pm 0.78$ \\
& $(0.92-3.17)$ \\
\hline
\end{tabular}

gaseous $\mathrm{SO}_{2}$ and particulate $\mathrm{SO}_{4}^{2-}$ were determined and deposition fluxes were obtained. Dry deposition flux of $\mathrm{SO}_{4}^{2-}$ on Cassia leaf has been determined by direct measurement. The dry deposition flux obtained by the current parameterization method is in the range of dry deposition flux obtained experimentally on natural surfaces (Cassia siamea).

\section{Acknowledgements}

We wish to thank Prof. Satya Prakash, Ex-Head and Prof. L.D. Khemani, Head, Department of Chemistry and Dr. K. Hansraj, Department of Mechanical Engineering for providing help and necessary facilities. The financial assistance from DST (Project No. SR/FTP/ES-57/2003) is gratefully acknowledged. Dr. B.B. Rao, Princiapl, Technical College of the Institute is gratefully acknowledged for kind encouragements.

\section{REFERENCES}

[1] P. J. Hanson and S. E. Lindberg, Atmospheric Environment, Vol. 25A, No. 8, 1991, pp. 1615-1634.

[2] R. Delmas and J. Serrvant, In: H. Rodhe and R. Herrera, Eds. Acidification in Tropical Countries, 1988, Wiley, Chichester, pp. 43-72.

[3] J. N. Galloway, G. E. Likens and M. E. Hawley, Science 1984, Vol. 226, pp. 829-831.

[4] B. B. Hicks, D. D. Baldocchi, T. P. Meyers, R. P. Hosker Jr. and D. R. Matt, "A Preliminary Multiple Resistance Routine for Deriving Dry Deposition Velocities from Measured Quantities," Water, Air and Soil Pollution, Vol. 36, No. 3-4, 1987, pp. 311-330. doi:10.1007/BF00229675

[5] A. S. Thom, In: J. L. Monteith, Ed. Vegetation and Atmosphere, Academic Press, London, 1975, pp. 58-109.

[6] J. A. Garland, “The Dry Deposition of Sulphur Dioxide to 
Land and Water Surfaces," Proceedings of the Royal Society (A), Vol. 354, No. 1678, 1977, pp. 245-268. doi:10.1098/rspa.1977.0066

[7] M. L. Wesley and B. B. Hicks, "Some Factors that Affect the Deposition Rates of Sulfur Dioxide and Similar Gases on Vegetation," Journal of Air Pollution Control Association, Vol. 27, No. 11, 1977, pp. 1110-1116. doi:10.1080/00022470.1977.10470534

[8] D. Fowler, "Dry Deposition of $\mathrm{SO}_{2}$ on Agricultural Crops," Atmospheric Environment, Vol. 12, No. 1-3, 1978, pp. 369-373. doi:10.1016/0004-6981(78)90219-6

[9] J. A. Businger, "Evaluation of the Accuracy with Which Dry Deposition Can Be Measured with Current Micrometeorological Techniques," Journal of Applied Meteorology, Vol. 25, 1986, pp. 1100-1124. doi:10.1175/1520-0450(1986)025<1100:EOTAWW $>2.0$. $\mathrm{CO} ; 2$

[10] J. H. Seinfeld and S. N. Pandis, "Atmospheric Chemistry and Physics: From Air Pollution to Climate Change," John Wiley and Sons Inc., Hoboken, 1998.

[11] M. L. Wesley and B. B. Hicks, Atmospheric Environment 2000, Vol. 34, pp. 2261-2282.

[12] J. E. Pleim, A. Venkatram and R. J. Yamartino, "ADOM/TADAP Model Development Program: The dry Deposition Module," Ontario Ministry of Environment, Rexdale, 1984, p. 4.

[13] J. Padro and G. C. Edwards, Atmospheric-Ocean, Vol. 29, 1991, pp. 667-685.

[14] J. Padro, "Summary of Ozone Dry Deposition Velocity Measurements and Model Estimates over Vineyard, Cotton, Grass and Deciduous Forest in Summer," Atmospheric Environment, Vol. 30, No. 13, 1996, pp. 23632369. doi:10.1016/1352-2310(95)00352-5

[15] J. S. Chang, R. A. Brost, S. A. Isaksen, S. Madronich, P. Middleton, W. R. Stockwell and J. Walcek, Journal of Geophysical Research, Vol. 92, No. 14, 1987, pp. 681-700.

[16] C. J. Walcek, R. A. Brost, J. S. Chang and M. L. Wesley, Atmospheric Environment, Vol. 20, 1986, pp. 949-964.

[17] M. L. Wesely, Atmospheric Environment, Vol. 23, No. 6, 1989, pp. 1293-1304.

[18] J. L. Walmsley and M. L. Wesely, Atmospheric Environment, Vol. 30, 1996, 1181-1188.
[19] J. W. Erisman and G. P. J. Draaijers, "Atmospheric Deposition in Relation to Acidification and Eutrophication," New York, Elsevier, 1995.

[20] E. C. Voldner, L. A. Barrie and A. Sirois, Atmospheric Environment, Vol. 20, 1986, pp. 2101-2123.

[21] B. B. Hicks, D. D. Baldocchi, R. P. Hosker Jr., B. A. Hutchison, D. R. Matt, R. T. McMillen, L. C. Satterfield, "NOAA Technical Memorandum ERL ARL-141," 1985, pp. 1-65.

[22] T. P. Meyers and D. D. Baldocchi, Tellus, Vol. 40B, 1988, pp. 270-284.

[23] D. R. Matt and J. D. Womack, Proceedings of the quadrennial Ozone Symposium 1988 and Tropospheric Ozone Workshop, A. Deepak Publishing, Hampton, 1989, pp. 490-493.

[24] J. Padro, G. den Hartog and H. H. Neumann, Atmospheric Environment, Vol. 25A, 1991, pp. 1689-1704.

[25] D. W., Stocker, D. H. Stedman, K. F. Zeller, W. J. Massman and D. G. Fox, "Fluxes of Nitrogen Oxides and Ozone Measured by Eddy Correlation over a Shortgrass Prairie," Journal of Geophysical Research, Vol. 98, No. D7, 1993, 12619-12630. doi:10.1029/93JD00871

[26] L. W. A. Van Hove, Thesis, University of Wageningen, Wageningen, 1989.

[27] C. I. Davidson and Y. L. Wu, In: S. E. Lindberg, A. L. Page and S. A. Norton, Eds., Acidic Precipitation, Springer Verlag, New York, 1990, pp. 103-216.

[28] R. M. Harrison and R. Perry, "Handbook of Air Pollution Analysis," 2nd Edition, Chapman Hall, New York, 1986. doi:10.1007/978-94-009-4083-3

[29] K. W. Nicholson, Atomspheric Environment, Vol. 22, 1988, pp. 2653-2666.

[30] E. Meszaros, D. J. Moore and J. P. Lodge Jr., "Sulfur Dioxide-Sulfate Relationships in Budapest," Atomspheric Environment, Vol. 11, No. 4, 1977, pp. 345-349. doi:10.1016/0004-6981(77)90162-7

[31] A. J. Alkenzweeny and D. C. Powell, "Estimation of Transformation Rate of $\mathrm{SO}_{2}$ to $\mathrm{SO}_{4}$ from Atmospheric Concentration Data," Atmospheric Environment, Vol. 11, No. 2, 1977, pp. 179-182.

doi:10.1016/0004-6981(77)90223-2 